\title{
Does Wine Price Percent Change Relate to an Expert Third Party Opinion? A Quick Look at One of the Gurus of Wine Ratings-An Abstract
}

\section{Christian Bushardt}

\begin{abstract}
Previous research has looked at several gurus of wine ratings and the relationship between their rating and price in French, New Zealand, and other geographic markets (Horowitz 2002; Ali 2008). Yet, to the author's knowledge, Robert Parker remains conspicuously absent in some areas of statistical inquiry, given his high level of prominence in the wine ratings industry. This paper examines the empirical support for Robert Parker's Wine Advocate's wine ratings relationship with price percentage change in domestic wines produced in 2011. Utilizing the hedonic price function and signal theory, Robert Parker's wine rating, in addition to several control variables, is empirically analyzed in a study utilizing over 800 observations.
\end{abstract}

References Available Upon Request.

\author{
C. Bushardt $(\bowtie)$ \\ Louisiana Tech University, Ruston, LA, USA \\ e-mail: CAB088@latech.edu
}

